\title{
The importance of cardiopulmonary arrest registry
}

\begin{abstract}
Since 1991, the International Liaison Committee on Resuscitation (ILCOR) applies registry templates to register cardiopulmonary arrest events and the treatment given to the patient in every case. This information is registered in a database that is useful to improve the cardiopulmonary resuscitation guidelines. For this reason, the ILCOR has introduced some changes to the registry template in several occasions, in order to obtain better results. The information collected on the registry templates is also useful for an epidemiological approach to the cardiopulmonary arrest. Unfortunately, this template is whether not applied or not correctly applied in many countries. The changes on the ILCOR's registry aim to facilitate the filling of the form. National and Local Health Services must implement its use, since it will allow to improve CA information all over the world.
\end{abstract}

Submitted: 08 July 2016; Accepted: 06 August 2016; Published online: 11 August 2016

Keywords: Cardiac arrest - Cardiopulmonary resuscitation - Registry template.

Reporting cardiopulmonary arrest (CA) events, treatments and results on a specific template generates a large database that allows obtaining information to review current guidelines and thus to produce changes that will improve outcomes on Cardio Pulmonary Resuscitation (CPR). This is relevant, considering how difficult it is to develop randomized or controlled studies on this matter. Furthermore, the evidence to elaborate guidelines is based on observational studies; most of them are retrospective and cases - series studies. The Cardiac Arrest registry template is then an important source of information, as it helps forward the improvement of existing guidelines, and, it provides information about short and longterm results, about prognosis, epidemiology, and statistics on CA causes.

The most important scientific associations that investigate CPR met at Utstein Abbey- Norway in 1990, to establish the International Liaison Committee on
Resuscitation (ILCOR). This committee pursued the standardization of CA concepts, treatment criteria and the stimulation of the investigation on the subject. In 1991 the ILCOR first designed forms for recording out-of-hospital CA events [1], and - due to epidemiological divergences-developed a different form for in- hospital CA events, in 1997. This forms collected important CA-related core and supplementary data. This information has been essential to our knowledge on CPR [2].

\section{Use of the Registry Template}

In most countries, the CPR organization is led by volunteers' organizations and scientific societies instead of Governments or National Health Services [3]. For this reason, not many countries apply ILCOR's registry template. Colombian studies reveal that the CA template does not have a suitable quality $[4,5]$. A study conducted on a second level hospital in Colombia [6] tried to implement
Wilson Valencia ${ }^{1 *}$, Johnnie Smith Husbands² \& José Ricardo Navarro ${ }^{3}$

${ }^{1}$ Clínica Nuestra Anesthesiologist, Medicina Universidad Santiago de Cali, Colombia

${ }^{2}$ Anesthesiologist Coordinador National Resuscitation Committee of Colombia, Colombia

${ }^{3}$ Anesthesiologist, Universidad Nacional de Colombia, Colombia

*Author for correspondence:

Tel.: +7184511075

wilsonvalenciaa@hotmail.com 
the registry template during a four months period, in 2010. Even though physicians were instructed on how to use the template, it was only used in $14 \%$ of the 22 CPR cases reported during the study. Physicians argued they did not have enough time to complete the form.

The ideal conditions to perform CPR are not easy to measure. Therefore, it would be useful to have complete registry templates. There are no figures indicating how many countries are currently using the template.

\section{Evolution and Changes on the Registry Template}

In 2001 ILCOR met again in Utstein (Norway). The meeting led to the conclusion that several changes on the CPR education systems were needed, since the appropriation and retention of skills to perform CPR were not as high as expected. The importance of registry template data was corroborated [3].

In 2002, another symposium was held in Melbourne, Australia. There were no consensus yet, differences on the concepts regarding CPR maneuvers persisted [7]. Once again, the importance of having information about the results of CPR was confirmed. The time elapsed between the beginning of the CA and the beginning of the CPR and the use of the defibrillator were defined as crucial, regarding prognosis. Concerning the registry template, they concluded the lack of information about the time elapsed between the events and the CPR was customary. The main problems were in unwitnessed CA cases and the lack of consensus regarding concepts of CA and CPR.

Consequently, precise concepts were defined on all CPR aspects. The most important periods of time and the higher impact data to be registered on the template were also identified. Supplementary information such as the team arrival time, venous access and drugs administration were included in the template. It also was established that the information about the period of time between the events is more important than the report of the time between the events itself, considering that team's watches are not usually synchronized. Some periods of time are no longer recommended to be registered, such as: time of arrival beside the patient, time elapsed between arrival to the scene and arrival to the Emergency Room and time of intubation.

A new template was designed to be useful both for originating changes on clinical handling and for investigations. The form should be the same for inhospital and out-of-hospital CA events, applicable on adults and children. The database should be available at international, national and local levels, guaranteeing the confidentiality of the information but should be clear enough for the general public and the investigators. The emphasis was also put on the importance of obtaining post-CA data. This originated the so-called Utstein- style, which was adopted by all the CPR services $[8,9]$. This form was applied in North America, Europe, Australia and Japan. It originated 584 bibliographic quotations in 50 countries. Nevertheless, there were still differences related to the CA and CPR concepts. After a review on 13 countries, many different definitions of the events were found. A third of the events reports did not have a suitable quality. This led the ILCOR to try a more effective template.

Two more meetings had place in Vienna (Austria) in 2012 and in Melbourne (Australia) in 2013 [10]. Those meetings allowed concluding that the latter form could not produce information about the variety of the population nor about the quality of the CPR offered or the quality of life of the surviving patients. Also, it led to the conclusion that in- hospital and out-of-hospital CA epidemiology are different. For that reason, it appeared necessary to design a different template for each one of them. The out-hospital CA events form (Figure 1) was published, while in-of-hospital CA events form has not been published yet.

The new registry template pretends to be more effective by following the patient's handling as a "roadmap"; from outside the hospital to the arrival to the hospital. It should facilitate obtaining data such as the return of spontaneous circulation, the survival to the event and to the discharge and the neurological results. It is also useful to evaluate the Emergency Services [11-13], the availability of an Automatic Extern Defibrillator and the organ donation.

This new form is divided in 5 phases:

System: Defines the population served, the emergency services, the number of CA events and the reasons argued not to perform CPR.

Dispatch: Describes the operation of emergency services, its methods and codes and its impact on the process.

Variables of the patient: Provides information about demographic data, comorbidity, CA cause, first monitored rhythm, localization of the event, information whether the event was witnessed or not, response to different handling.

Process: Provides information about the response time of the emergency services, and the time of the first defibrillation.

Outcome: Informs about the number of survived events, the survival to discharge, the 30-day survival, the outcome and the neurological prognosis. For the latter, the use of scales such as the CPC (Cerebral Performance Categories) is suggested [8]. This scale grants a score, according to the patient's state:

1. Good brain performance, patient is conscient, alert, able to work, may have a slight neurological affectation or psychological deficit; 


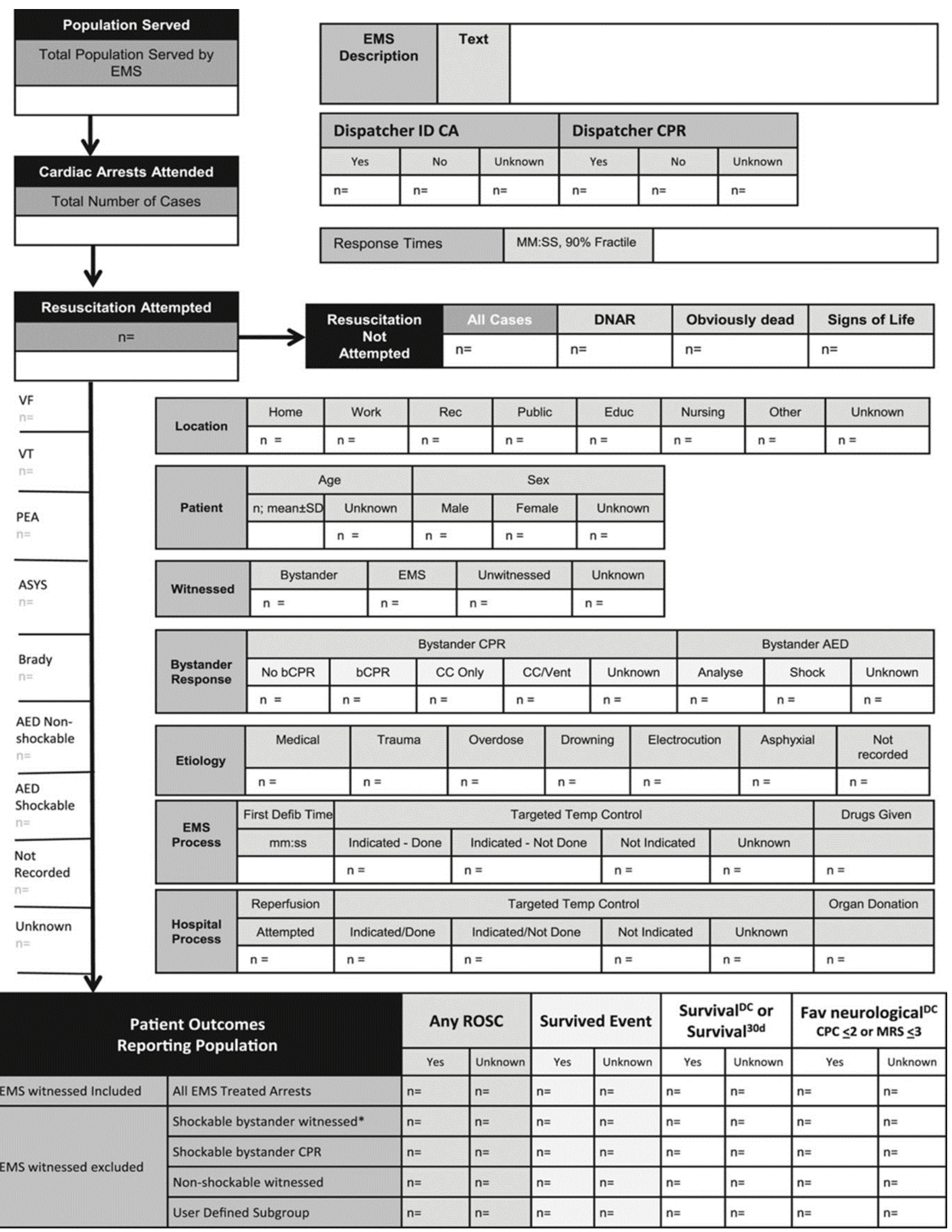

Figure 1. Ustein-style out-of-hospital CA registry. Taken from Gavin.D. Perkins. Circulation 2015. AED: Automated External Defibrillator; ASYS: Asystole; bCPR: bystander Cardiopulmonary Resuscitation; BRADY: Bradycardia; CA: Cardiac Arrest; CC: Chest Compressions; CPC: Cerebral Performance Category; CPR: Cardiopulmonary Resuscitation; DC: Discharge; DEFIB: Defibrillation; DNAR: Do Not Attempt Resuscitation; EDUC: Educational Institution; EMS: Emergency Medical Services; FAV: Favorable; ID: Identified; mRS: modified Rankin Scale; PEA: Pulseless Electrical Activity; REC: Sports/Recreation Event; ROSC: Return of Spontaneous Circulation; TEMP: Temperature; VENT: Ventilations; VF: Ventricular Fibrillation; and VT: Ventricular Tachycardia. *Utstein comparator group (system efficacy). 


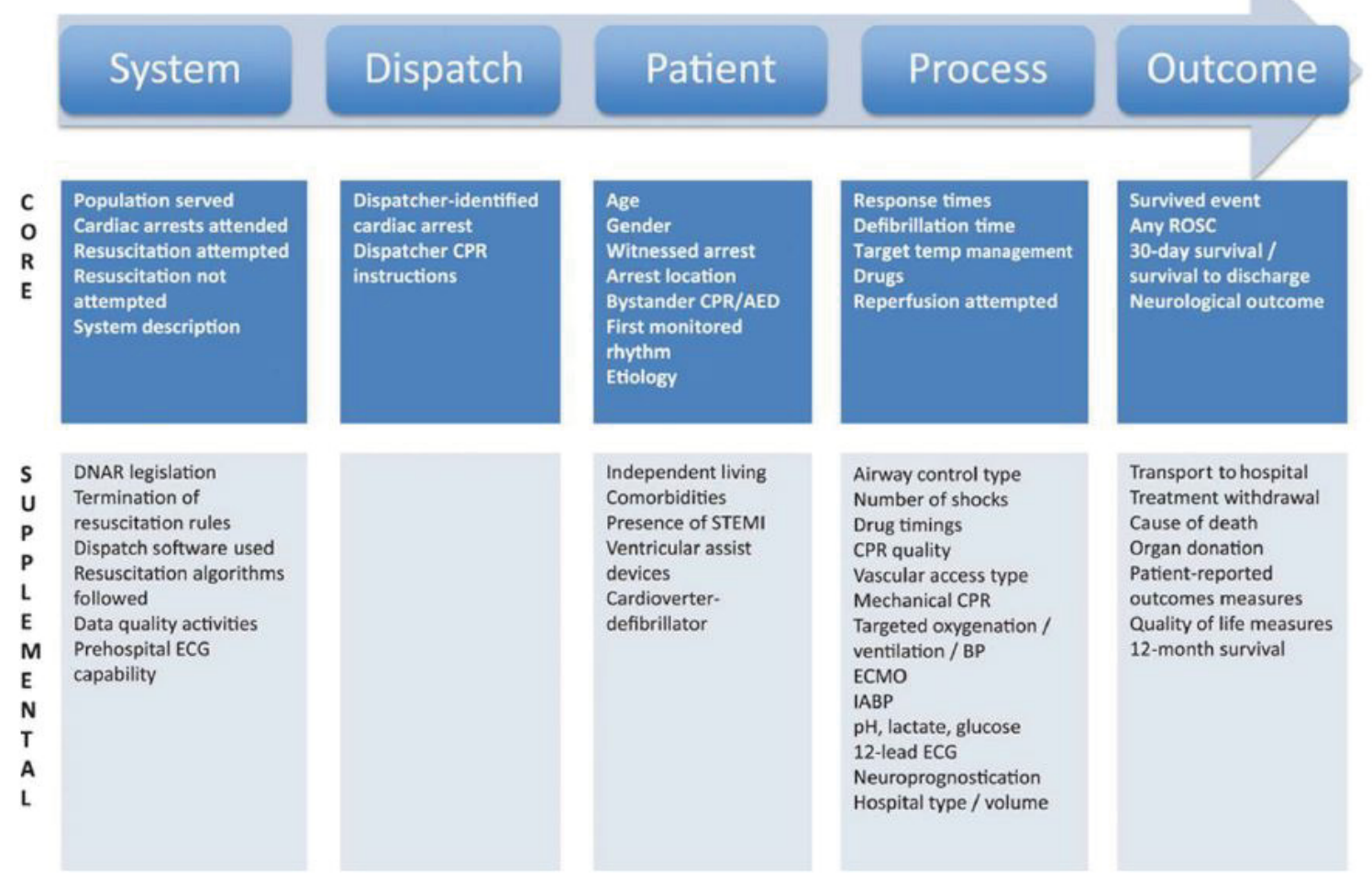

Figure 2: Information phases on CA registry. Taken from Gavin.D. Perkins, Circulation 2015.

2. Moderate brain capacity, patient is conscient, enough brain capacity to perform daily activities;

3. Serious brain incapacity, patient is conscient, needs assistance to perform daily activities;

4. Patient in coma or vegetative state, any coma degree without signs of brain death. Patient is not alert even though could seem as if patient was awake, no interaction with environment;

5. Brain death.

The new form also informs about data catalogued as core and supplementary (Figure 2).

The decisions of not to perform CPR in some patients and the reasons argued, are determinant. Many articles have focused on that matter. When there are no-resuscitation orders signed by the patient, they must be respected. Evidently, it is impossible to obtain an informed consent, as it would be done for any other procedure, on a conscientious patient. Nevertheless, there are cases on which the non-performance of CPR is recommended for human and ethical reasons. Thus, no maneuvers should be performed on subjects that present obvious signs of death. Neither should they be performed on terminal patients or on those patients on dreadful conditions, with bad prognosis or little life expectancy. In those cases, the CA is the end of their death process and performing it would not produce any benefit but would harm the patient and his/her family. No health professional is obliged to perform that action. In those cases, the physicians responsible for the patient and the family will previously sign the non- resuscitation order. Not every death should come with a CPR maneuver [14].

\section{Conclusion}

Survival rate on patients on which CPR were performed is still very low. On average, it corresponds to less than $20 \%$ of cases [15-17]. Neurological consequences are common on survival CPR patients but its quantification is limited and changeable. Consequences can vary from slight cognitive damage to devastating brain death cases. The ILCOR has made a great effort to improve CPR outcomes, by publicizing the guidelines [18-20] standardizing definitions and re- designing the CPR registry template. Even though the outcomes still show low figures on survival of resuscitated patients, there have been improvements since the beginning of CPR, during the 60's. This is due to all these efforts and to the use of CA registries templates in many countries, since it works as a feedback for the guidelines designers. There is reported information about the most effective maneuvers, and methodologies like chain of survival that allows the resuscitators to easily remember the process step by step, without wasting time on useless handling/treatments/ 
processes. These maneuvers will improve CPR patients' prognosis.

The latter proves the importance of CA registry. Strategies to promote the filling of the template all over the world must be designed. The studies conducted in Colombia [4-6] show that this cannot depend on emergency services, hospitals or scientific society's good

\section{References}

1. Cummins RO, Chamberlain DA, Abramson NS, et al. Recommended Guidelines for Uniform Reporting of Data From Out-of-Hospital Cardiac Arrest: The Utstein Style A Statement for Health Professionals From a Task Force of the American Heart Association, the European Resuscitation Council, the Heart and Stroke Foundation of Canada, and the Australian Resuscitation Council. Circulation. 184 (1991).

2. Idris AH, Becker LB, Ornato P, et al. Utstein-style guidelines for uniform reporting of laboratory cpr research a statement for healthcare professionals from a task force of the american heart association, the american college of emergency physicians, the american college of cardiology, the european resuscitation council, the heart and stroke foundation of canada, the institute of critical care medicine, the safar center for resuscitation research, and the society for academic emergency medicine. Circulation. 94, 9 (1996).

3. Chamberlain DA, Hazinski MF. Education in Resuscitation, an ILCOR Symposium: Utstein Abbey: Stavanger, Norway: June 22-24, 2001. Circulation. 108, 2575-2594 (2003).

4. Navarro JR. Registro de paro cardiaco en el adulto. Rev. Fac. Med. Univ. Nac. Col. 53, 196-201 (2005).

5. Barragán G, Navarro JR, Marulanda N. Análisis de la calidad del Registro de Paro Cardíaco en casos de responsabilidad medicolegal en médicos generales, SCARE-FEPASDE 19992007. Rev Fa. Med. Univ. Nac. Col. 57, 5-17 (2009).

6. Valencia W, Navarro JR, Ramírez K, et al. Implementación del registro de paro cardiorespiratorio en un hospital de segundo nivel. Rev. Col. Anest. 39, 478-487 (2011).

7. Jacobs I, Nadkarni V. Cardiac Arrest and Cardiopulmonary Resuscitation Outcome Reports. Circulation. 110, 3385-3397 (2004).

8. Idris AH, Berg RA, Bierens J, et al. (2003) Recommended guidelines for uniform reporting of data from drowning: the "Utstein style". Circulation. 108, 2565-2574.

9. Berg M, Schexnayder S, Chameides L, et al. Part 13: Pediatric basic life support: 2010 American Heart Association Guidelines for Cardiopulmonary Resuscitation and Emergency Cardiovascular Care. Circulation. 3, 862-887 (2010). will. It should be imposed by Government regulations, just as the clinical history of death certificates. In that sense, legislative powers must get involved.

Different sorts of CA registry template can be designed, according to the epidemiology and the culture of the countries or the cities, but the Utsteinstyle must be preserved and its core and supplementary data should be reported as basic information.

10. Perkins GD, Jacobs IG, Nadkarni VM, et al. Cardiac Arrest and Cardiopulmonary Resuscitation Outcome Reports: Update of the Utstein Resuscitation Registry Templates for Out-of- Hospital Cardiac Arrest. Circulation. 132, 1286-1300 (2015).

11. Stub D, Smith K, Bray JE, et al. Hospital characteristics are associated with patient outcomes following out-of- hospital cardiac arrest. Heart. 97, 1489-1494 (2011).

12. Nehme Z, Bernard S, Cameron P, et al. Using a Cardiac Arrest Registry to Measure the Quality of Emergency Medical Service Care Decade of Findings From the Victorian Ambulance Cardiac Arrest Registry. Circ. Cardiovasc. Qual. Outcomes. 8, 56-66 (2015).

13. Jennett B, Bond M. Assessment of outcome after severe brain damage. Lancet. 1, 480-484 (1975).

14. Mohr M, Kettler D. Ethical aspects of resuscitation. Br. J. Anaesth. 79, 253-259 (1997).

15. Goldberger ZD, Chan PS, Berg RA, et al. Duration of resuscitation efforts and survival after in-hospital cardiac arrest: an observational study. The Lancet. 380, 1473-1481 (2012).

16. Eisenberg MS, Cummins RO, Larsen MP. Numerators, denominators, and survival rates: reporting survival from out-of-hospital cardiac arrest. Am. J. Emerg. Med. 9, 544-546 (1991).

17. Herlitz J, Ekstrom L, Wennerblom B, et al. Survival in patients found to have ventricular fibrillation after cardiac arrest witnessed outside hospital. Eur. Heart. J. 15, 1628-1633 (1994).

18. Matiz H. Gómez H, Gómez A. La reanimación Intrahospitalaria = Código azul. Anexo 2. Soporte Vital Básico y Avanzado. Análisis crítico de las nuevas Guías 2005. EBM. Colombia. Edit. Distribuna. (2007).

19. Navarro-Vargas JR, Matiz-Camacho H, Osorio-Esquivel JE. Manual de práctica clínica basado en la evidencia: Reanimación cardiocerebropulmonar. Rev. Col. Antest. 43, 9-19 (2015).

20. http://www.cercp.org/images/stories/recursos/Guias\%202015/ Guidelines- RCP-AHA-2015-Full.pdf 